\title{
Time-Dependent Effects of Starvation on Serum, Pituitary and Hypothalamic Leptin Levels in Rats
}

\author{
P. VUJOVIC ${ }^{1}$, I. LAKIC ${ }^{1}$, D. LAKETA ${ }^{1}$, N. JASNIC ${ }^{1}$, S. F. DJURASEVIC ${ }^{1}$, G. CVIJIC ${ }^{1}$, \\ J. DJORDJEVIC ${ }^{1}$ \\ ${ }^{1}$ Institute of Physiology and Biochemistry, Faculty of Biology, University of Belgrade, Belgrade, \\ Serbia
}

Received December 28, 2010

Accepted February 16, 2011

On-line July 19, 2011

\section{Summary}

Leptin is produced by white adipose tissue and other cell types and is involved in both short- and long-term appetite control. Here we studied effects of starvation on serum, pituitary and hypothalamic levels of leptin during $72 \mathrm{~h}$ period. Each of the starved groups was sacrificed simultaneously with the group of ad libitum fed animals. The progression of the discrete starvation response phases was monitored by testing the blood glucose, free fatty acid, urea and corticosterone levels. Starvation caused biphasic increase in corticosterone and free fatty acid levels, and significant but transient decrease in urea and glucose levels. Starvation also abolished diurnal rhythm of changes in leptin concentrations in serum and hypothalamic and pituitary tissues. Only $6 \mathrm{~h}$ starving period was sufficient to lock serum leptin at low levels, whereas $12 \mathrm{~h}$ were needed to silence leptin production/ secretion in hypothalamus for the whole examined period. In contrast, leptin production by pituitary tissues of starved animals required $24 \mathrm{~h}$ to reach minimum, followed by full recovery by the end of starvation period. These results indicate the tissue specific pattern of leptin release and suggest that the locally produced leptin could activate its receptor in pituitary cells independently of serum levels of this hormone.

\section{Key words}

Starvation • Leptin • Hypothalamus • Pituitary • Rat

\section{Corresponding author}

P. Vujovic, Institute of Physiology and Biochemistry, Faculty of Biology, University of Belgrade, 11000 Belgrade, Serbia. E-mail: predragv@bio.bg.ac.rs

\section{Introduction}

Starvation refers to biological condition wherein a postabsorptive animal, otherwise willing to eat, is unable to do so as a result of some extrinsic limitation on food resources. Characterized by the choice of primary physiological fuel, metabolic response to total food deprivation could be divided into three discrete, sequential phases (McCue 2010). The first phase is a short period of acclimatization to food deprivation, during which glycogenolysis occurs. The second phase is characterized by further protein sparing and the energy requirements are predominantly met through lipid oxidation (Drackley et al. 2000). The transition into the final proteolytic phase is marked by the simultaneous increase of both blood urea and corticosterone (CORT) concentration. A rise in locomotor activity, also called „food seeking behaviour", is another feature of prolonged starvation and it coincides with the expansion in the protein utilization (Koubi et al. 1991). The described changes in carbohydrate, lipid and protein metabolism in the course of food deprivation apply to various species, including rats.

Leptin originally became known as a potent anorexigenic hormone due to its involvement in appetite control and body mass regulation. This versatile peptide hormone, a product of obesity gene, is secreted into the bloodstream primarily by white adipose tissue (WAT), and acts on hypothalamus to decrease appetite (Zhang et al. 1994). Under the normal physiological circumstances, circulating leptin concentration positively correlates with both body mass index (BMI) and the total amount of fat 
depots (Fruhbeck et al. 1998).

The discovery of extra-adipose leptin expression and the ubiquitous distribution of leptin receptors have indicated leptin relevancy in a myriad of physiological processes such as reproduction, immunity, angiogenesis, wound healing, bone remodeling and cardiovascular function (Banks 2004). Apart from being able to uptake leptin from blood stream, the hypothalamus was also shown to produce leptin (Morash et al. 1999). It acts within the arcuate nucleus stimulating cocaine and amphetamine regulated transcript/ proopiomelanocortin and inhibiting neuro-peptide Y/agouti related peptide expression (McMinn et al. 2000). These neuropeptides further act to either stimulate or inhibit food intake (Abhiram 2004).

It is also known that the pituitary gland has the potential for the local leptin production (Crane et al. 2007). Unlike WAT, in which the newly synthesized leptin is immediately released, the storage of leptin in the secretory granules indicates that the adenohypophyseal cells retain leptin until stimulated (Popovic et al. 2001). The colocalization studies with leptin and pituitary hormones suggested that the following lines of anterior pituitary cells produce leptin: corticotrophs (70\% positive for leptin), gonadotrophs (29-33\% positive for leptin), somatotrophs (21\% positive for leptin), thyrotrophs (32\% positive for leptin) and folliculostellate cells (64\% positive for leptin) (Vidal et al. 2000). Various isoforms of leptin receptor have also been identified in the pituitary (Lloyd et al. 2001).

In this study, we compared change in the serum, intrapituitary and intrahypothalamic leptin levels throughout the different phases of the metabolic response to starvation. In order to establish the duration of each of these phases, we also assessed the set of auxiliary metabolic parameters, including the blood glucose, free fatty acid (FFA), urea and CORT levels.

\section{Materials and Methods}

Adult male rats of Wistar strain bred in the vivarium of the Belgrade University Faculty of Biology were used in this experiment. Two rats were housed per cage under the controlled temperature conditions $\left(21 \pm 1{ }^{\circ} \mathrm{C}\right)$ and lighting $(12 \mathrm{~h}$ light $-12 \mathrm{~h}$ of darkness). The food was removed at the onset of the dark phase $(6 \mathrm{pm})$ and the groups of animals remained food deprived for $6,12,24,48$ or $72 \mathrm{~h}(\mathrm{n}=6)$. Each of the starved groups was sacrificed simultaneously with the group of ad libitum fed rats $(\mathrm{n}=6)$. All the animals had free access to tap water. The experiment was performed according to the rules for animal care proposed by the Serbian Laboratory Animal Science Association, a member of the Federation of European Laboratory Animal Science, and approved by the Ethics Committee of the Faculty of Biology, University of Belgrade.

Animals were decapitated without anesthesia with a guillotine (Harvard-Apparatus, Holliston, MA). Blood was collected from the trunk. The pituitary glands and brains were quickly excised. Hypothalami were removed and then frozen at $-80{ }^{\circ} \mathrm{C}$ until further use. Serum was frozen for glucose, FFA, urea, leptin and CORT determination. Serum leptin was measured using ELISA kit (Invitrogen, Camarillo, CA 93012) and the values were expressed as $\mathrm{ng} / \mathrm{ml}$. Serum CORT was determined with a radioimmunoassay kit (ICN Biochemicals, Costa Mesa, CA) and the values were expressed as $\mu \mathrm{g} / \mathrm{ml}$ serum. Blood glucose concentration was measured with an Exac-tech glucose analyzer (Medisense Inc., Cambridge, MA) using Dextrostix reagent strips. Serum FFA concentration was determined by the colorimetric method of Ducombe (1964). The values were expressed as $\mathrm{mmol} / \mathrm{l}$ serum.

For western blotting, $25 \mu \mathrm{l}$ of either pituitary or hypothalamic samples, with protein concentration of $1 \mathrm{mg} / \mathrm{ml}$, were run on a $20 \%$ SDS polyacrylamide gel (120 V, Criterion Cell, Bio-RAd, Hercules, CA) and then transferred (overnight, $20 \mathrm{~mA}$ per gel, Criterion blotter, Bio-Rad) onto 0.45-mm PVDF membranes. After Ponceau $\mathrm{S}$ staining and destaining, membranes were blocked for $3 \mathrm{~h}$ in $5 \%$ nonfat dry powder milk (Santa Cruz) in Tris-buffered saline containing $0.1 \%$ Tween 20 (TBST). After that, the blots were incubated with the primary antibody against leptin (1:3500 dilution, Abcam), overnight at $4{ }^{\circ} \mathrm{C}$ on a shaker. Then the blots were washed four times for $15 \mathrm{~min}$ in TBST before the $1 \mathrm{~h}$ incubation with the horseradish peroxidase conjugated secondary antibody (1:5000 dilution, Abcam). The blots were re-washed four times for $15 \mathrm{~min}$ in TBST. Lastly, the ECL+ (Abcam) was added onto the PVDF membranes for $5 \mathrm{~min}$. After draining the excessive ECL+ solution, the immunoreactive bands were detected in the dark chamber. The quantification was performed with the Image Quant 5.2 (Molecular Dynamics) program.

The ANOVA one-way and Tukey's posterior multiple comparison tests were employed for comparison of the experimental groups. The values were expressed as mean \pm S.E.M. values of six animals, the level of 
significance being set at $\mathrm{p}<0.01$ or higher.

\section{Results}

Figure 1 illustrates the time course effect of starvation on blood glucose, FFA, urea and CORT concentration. Starvation caused a rapid and significant drop in glucose levels during first $12 \mathrm{~h}$, followed by an additional decrease at $18 \mathrm{~h}$ treatment that lasted for at least $30 \mathrm{~h}$. At the end of starvation period, a small increase in glucose levels was observed, which was still significantly lower than in controls. Similar profile of changes was observed in urea levels during starvation, but differences between controls and starved animals were smaller compared to glucose levels. In contrast, FFA and CORT levels increased in biphasic manner in starved animals, with an initial small but statistically significant increases during the initial phase of starvation followed by a substantial growth during the second phase of starvation. The secondary growth in FFA and CORT production was detected 24 and $42 \mathrm{~h}$ after removal of food, respectively.

Figure 2 summarizes changes in serum leptin in starved animals. The circadian rhythm of the serum leptin production detected in control rats during first $24 \mathrm{~h}$ was completely abolished by food restriction. The leptin secretion decreased significantly $6 \mathrm{~h}$ after removal of food. The circulating levels of leptin dropped to the lower levels observed in control animals and stayed locked at that level throughout the whole examined period.

Like serum leptin content, the hypothalamic leptin contend decreased to the levels comparable to the bottom concentrations observed in controls, but $12 \mathrm{~h}$ of starvation was needed to reach that level (Fig. 3). In contrast, leptin concentration were significantly higher in the pituitary from starved animals during initial $12 \mathrm{~h}$, followed by a significant decrease during $36 \mathrm{~h}$ period and complete recovery of production at the end of starvation period (Fig. 4).

\section{Discussion}

The food deprivation was documented to induce the physiological shift away from carbohydratedominated catabolism toward lipid- or protein-dominated catabolism (Staples and Buck 2009). The blood glucose level is the central indicator of a body energy status and hence the most commonly measured physiological variable in starving animals. As expected, in our study

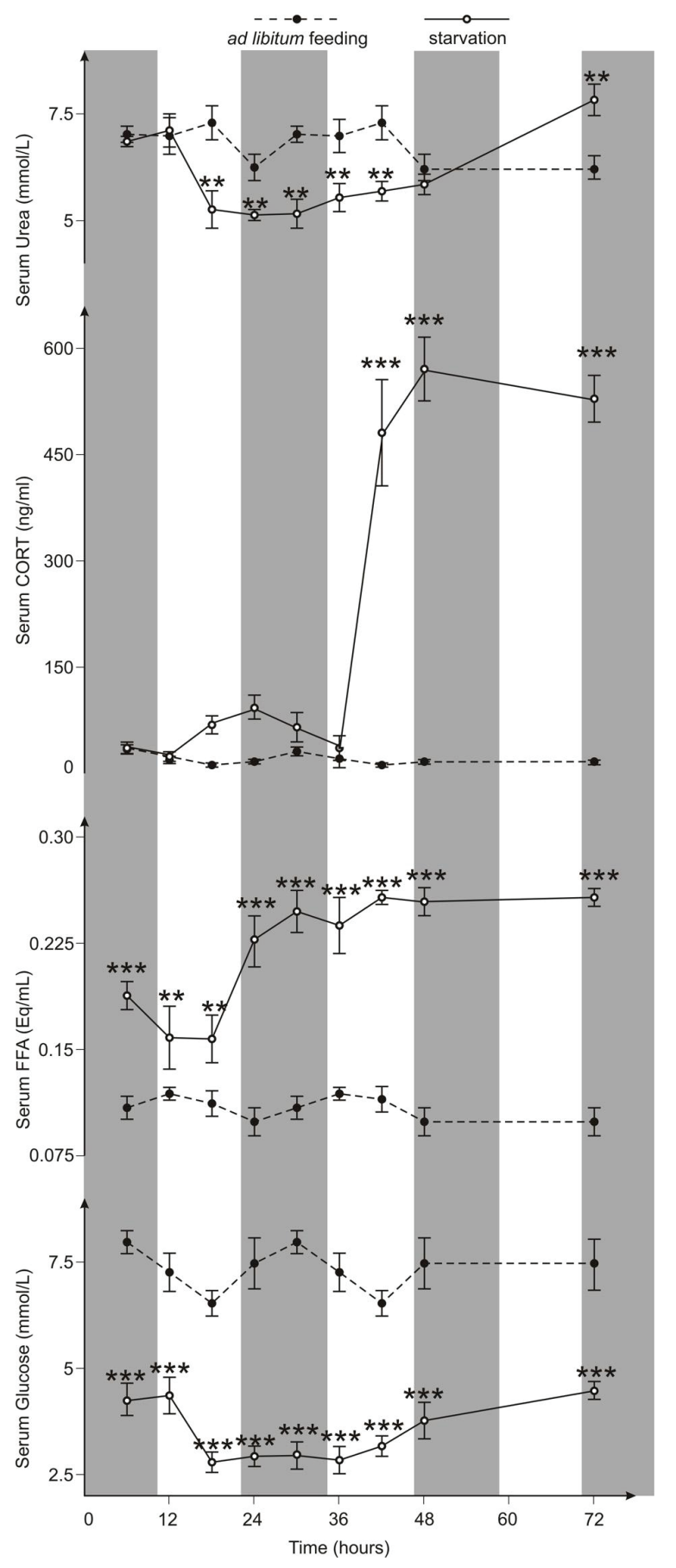

Fig. 1. Metabolic parameters in the serum of starved and $a o$ libitum fed rats: glucose (GLU), free fatty acid (FFA), urea and corticosterone (CORT). In this and following figures, gray areas indicate dark periods and white areas indicate light periods. Data shown are means \pm S.E.M. from six measurements per point and asterisks indicate significant differences between groups, $p<0.01$.

starvation induced hypoglycemia in the blood of all the starved groups. The reduction of circulating glucose is also relevant in terms of central food intake control, given the existence of hypothalamic glucoso-responsive neurons (Bray 1996). It is well known that the lack of caloric intake stimulates hormone sensitive lipase (HSL), 


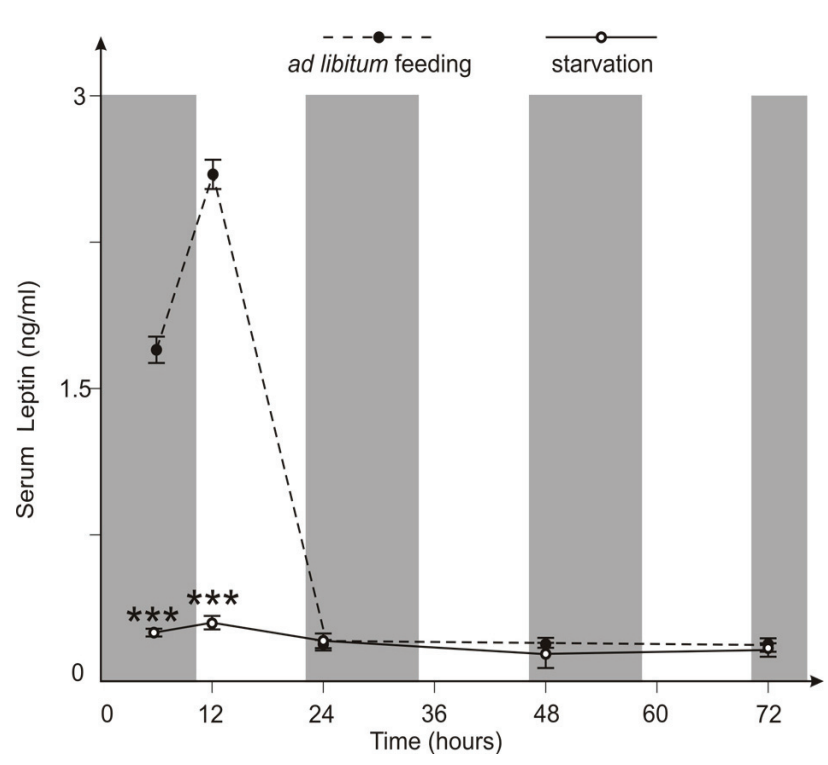

Fig. 2. Leptin concentration in the serum of starved and $a a$ libitum fed rats. Data shown are means \pm S.E.M. from six measurements per point and asterisks indicate significant differences between groups, $\mathrm{p}<0.01$.

which mobilizes glycerol and unesterified fatty acids from triglyceride depots (Drackley et al. 2000). Our findings that the serum FFA level was elevated in each examined group are in accordance with those of Drackley et al. (2000) FFAs further undergo $\beta$-oxidation and serve as an alternative source of energy. Significant decrease in blood glucose between 12 and $18 \mathrm{~h}$ starved groups in combination with the significant rise in the serum FFA between the 18 and $24 \mathrm{~h}$ starved groups, indicates that the transition from phase 1 to phase 2 took place between the $18^{\text {th }}$ and $24^{\text {th }}$ hour of food deprivation.

The blood urea is also regularly quantified in starving animals, given that they catabolize physiological fuels in descending order, i.e. firstly carbohydrates, then lipids and finally proteins (Castellini and Rea 1992). With the exception of the group subjected to $72 \mathrm{~h}$ starvation, we observed that circulating urea concentration remained beneath or at the control level. However, the permanently increasing trend in blood urea level as off the $30^{\text {th }}$ hour of food restriction and the prominent peak of the blood CORT detected after the $42^{\text {nd }}$ hour of starvation, suggest that the third, proteolytic phase of metabolic response to starvation commenced between 36 and 42 hours after food removal. Besides, the food seeking behavior was observed in the animals, which fasted 42 hours and more, which was proved to coincide with the rise in protein catabolism (Koubi et al. 1991).

Leptin, the product of the obese gene, is secreted

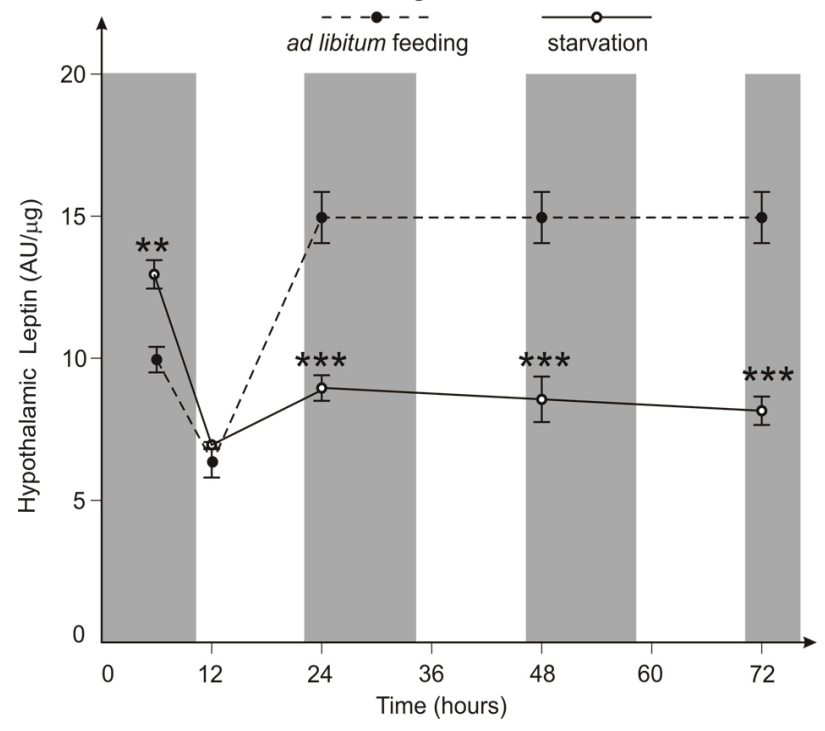

Fig. 3. Leptin concentration in the hypothalamus of starved and ad libitum fed rats. Data shown are means \pm S.E.M. from six measurements per point and asterisks indicate significant differences between groups, $p<0.01$.

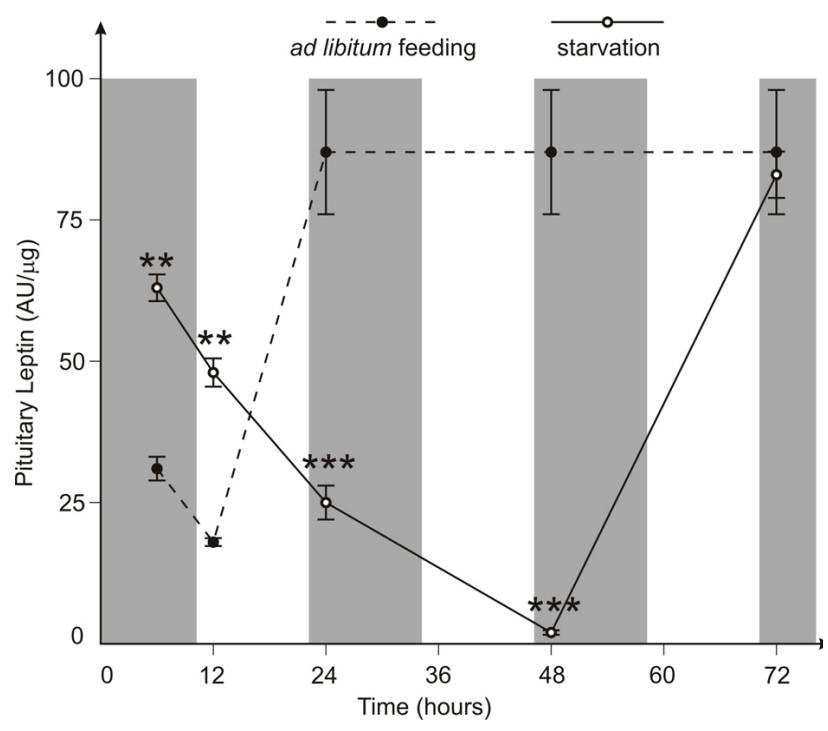

Fig. 4. Leptin concentration in the pituitary of starved and $a a$ libitum fed rats. Data shown are means \pm S.E.M. from six measurements per point and asterisks indicate significant differences between groups, $\mathrm{p}<0.01$.

by peripheral adipocytes and the hormone is long recognized to be involved in the regulation of energy homeostasis (Friedman and Halaas 1998). Quite expectedly, in the light of its role as a satiety signal, we found that leptin concentration was decreased in the serum of the animals, which starved for 6 and $12 \mathrm{~h}$. The absence of significant differences in serum leptin levels between the groups food deprived for 24, 48 and $72 \mathrm{~h}$, and the corresponding control group, could be explained by the timing of blood sampling. Namely, all of these 
groups were sacrificed at the onset of the dark phase $(6 \mathrm{pm})$ in the vivarium lighting regime. That is the time of a day when rats normally begin to eat and therefore circulating leptin level was expected to be at the lowest point even in the blood of normally fed rats (Sinha et al. 1996). The lack of significant differences among the leptin concentration level in the blood of any of the groups starved implies that the food deprivation readily down-regulated both leptin synthesis in and release from WAT to a minimal level, which was also detected in the circulation of ad libitum fed rats at the beginning of the dark phase. This observation is in accordance with data that leptin secretion from the WAT is in the direct proportion to the WAT glucose uptake (Wendy et al. 1998). In our study, the blood glucose level has already been significantly reduced as early as after $6 \mathrm{~h}$ of starvation, which undoubtedly led to the decreased rate of glucose metabolism in the WAT and ultimately to the suppression of leptin synthesis and its subsequent release into circulation.

It is also noteworthy that the serum leptin level has been decreased even before the lipolytic phase began. This acute, adiposity independent decrease of leptin production in response to short term starvation is driven by evolutionary pressure to increase energy intake and conservation before body fat stores are significantly decreased (Weigle et al. 1997).

All endocrine pituitary cell types express leptin receptor. However, leptin is localized in the specific subtypes of anterior pituitary cells indicating cell typespecific production of leptin in the anterior pituitary (Lloyd et al. 2001). The changes in intrapituitary leptin content observed in our study were unexpected. Leptin concentration was elevated in the groups subjected to 6 and $12 \mathrm{~h}$-starvation. However, leptin concentration was then decreased below the control level after 24 and $48 \mathrm{~h}$ of food deprivation, but it once again reached the control level $72 \mathrm{~h}$ after the food abolishment. The increase in the pituitary leptin level was neither preceded nor subsequently followed by the rise of the circulating leptin concentration. This indicates that the synthesis within the pituitary most probably accounts for the increase of leptin level in the gland and that this exra-adiposely produced leptin predominantly acts in paracrine and/or autocrine fashion (Yeung et al. 2006), rather than contributing to the overall circulating leptin pool.

Leptin enters the central nervous system through the blood-brain barrier, but its expression was also documented in specific brain regions, including hypothalamus (Morash et al. 1999). In our research, the hypothalamic leptin increased after $6 \mathrm{~h}$ of food restriction. It then fell to the control level in the $12 \mathrm{~h}$ starved group and finally dropped below it as off the $24^{\text {th }}$ hour of food deprivation. This finding is in agreement with the previously published data that leptin mRNA was no longer detectable in hypothalamus after one day of starvation (Morash et al. 1999). It is known the leptin exerts the appetite-regulating role by acting on various groups of neurons in arcuate nucleus (Brady et al. 1990). It is worth mentioning that starvation induced decrease in serum leptin as soon as the blood glucose was lowered, but the reduction in hypothalamic leptin was not detected until the lipid stores were compromised. Based on different starving induced kinetics of the serum and hypothalamic leptin change, it could be hypothesized that adipose leptin production is responsible for short-term food intake, whereas the hypothalamically produced leptin predominantly regulates long-term energy homeostasis. The decreased availability of the circulating leptin, combined with the reducing leptin hypothalamic expression, eventually led to the decrease below the control level.

In summary, leptin concentration was changed by starvation in a time-dependent and tissue-specific manner. Food deprivation readily down-regulated leptin synthesis within the WAT to a certain minimal level, also characteristic for ad libitum fed rats at the beginning of the dark phase. On the other hand, the decrease in overall hypothalamic leptin content was shifted until lipolytic phase began, which is consistent with the leptin involvement in the long-term appetite control. Finally, the kinetics of pituitary-derived leptin in starved animals was unique, suggesting that locally produced hormone plays a specific role in this organ presumably acting in paracrine/autocrine fashion rather than contributing to overall leptin pool.

\section{Conflict of Interest}

There is no conflict of interest.

\section{Acknowledgements}

This work was supported by the Serbian Ministry of Science (Grant No. 173023). The authors wish to thank Aleksandar Bajic and Andrej Korenic for their help with making graphs. We would also like to express sincere appreciation to Stanko Stoilkovic for his guidance and advice he provided during the final shaping of this paper. 


\section{References}

BANKS WA: The many lives of leptin. Peptides 25: 331-338, 2004.

BRADY LS, SMITH MA, GOLD PW, HERKENHAM M: Altered expression of hypothalamic neuropeptide mRNAs in food restricted and food-deprived rats. Neuroendocrinology 52: 441-447, 1990.

BRAY GA: Static theories in a dynamic world: a glucodynamic theory of food intake. Obes Res 4: 489-492, 1996.

CASTELLINI MA, REA LD: The biochemistry of natural fasting at its limits. Experientia 48: 575-582, 1992.

CRANE C, AKHTER N, JOHNSON BW, IRUTHAYANATHAN M, SYED F, KUDO A, ZHOU YH, CHILDS G: Fasting and glucose effects on pituitary leptin expression. Is leptin a local signal for nutrient status? J Histochem Cytochem 55: 1059-1073, 2007.

DRACKLEY JK, D'MELLO JPF: Lipid metabolism. In: Farm Animal Metabolism and Nutrition. CABI Publishing, Wallingford, 2000, pp. 97-119.

FRIEDMAN JM, HALAAS JL: Leptin and the regulation of body weight in mammals. Nature 395: 763-770, 1998.

FRUHBECK G, JEBB SA, PRENTICE AM: Leptin: physiology and pathophysiology. Clin Physiol 18: 399-419, 1998.

KOUBI HE, ROBIN JP, DEWASMES G, LE MAHO Y, FRUTOSO J, MINAIRE Y: Fasting-induced rise in locomotor activity in rats coincides with increased protein utilization. Physiol Behav 50: 337-343, 1991.

LLOYD RV, LONG JIN L, TSUMANUMA I, VIDAL S, KOVACS K, HORVATH E, SCHEITHAUER BW, COUCE ME, BURGUERA B: Leptin and leptin receptor in anterior pituitary function. Pituitary 4: 33-47, 2001.

MCCUE MD: Starvation physiology: reviewing the different strategies animals use to survive a common challenge. Comp Biochem Physiol A Mol Integr Physiol 156: 1-18, 2010.

MCMINN JE, BASKIN DG, SCHWARTZ MW: Neuroendocrine mechanisms regulating food intake and body weight. Obes Rev 1: 37-46, 2000.

MORASH B, LI A, MURPHY PR, WILKINSON M, UR E: Leptin gene expression in the brain and pituitary gland. Endocrinology 140: 5995-5998, 1999.

MUELLER W, GREGOIRE F, STANHOPE K, MOBBS C, MIZUNO T, WARDEN C: Evidence that glucose metabolism regulates leptin secretion from cultured rat adipocytes. Endocrinology 139: 551-558, 1998.

POPOVIC V, DAMJANOVIC S, DIEGUEZ C, CASANUEVA F: Leptin and the pituitary. Pituitary 4: 7-14, 2001.

SAHU A: Leptin signaling in the hypothalamus: emphasis on energy homeostasis and leptin resistance. Front Neuroendocrinol 24: 225-253, 2004.

SINHA MK, OHANNESIAN JP, HEIMAN JL, KRIAUCIUNAS A, TEPHENS TW, MAGOSIN S, MARCO C, CARO JF: Nocturnal rise of leptin in lean, obese and non-insulin-dependent diabetes mellitus subjects. $J$ Clin Invest 97: 1344-1347, 1996.

STAPLES JF, BUCK LT: Matching metabolic supply and demand in energy-stresses animals. Comp Biochem Physiol 153: 95-105, 2009.

VIDAL S, COHEN S, HORVATH E, KOVACS K, SCHEITHAUER B, BURGUERA B, LLOYD RV: Subcellular localization of leptin in non-tumorous and adenomatous human pituitaries: An immuno-ultrastructural study. J Histochem Cytochem 48: 1147-1152, 2000.

WEIGLE DS, DUELL PB, CONNOR WE, STEINER RA, SOULES MR, KUIJIPER JL: Effects of fasting, refeeding and dietary fat restriction on plasma leptin levels. J Clin Endocrinol Metab 81: 561-565, 1997.

YEUNG CM, CHAN CB, LEUNG PS, CHENG CH: Cells of the anterior pituitary. Int J Biochem Cell Bio 38: 1441$1449,2006$.

ZHANG Y, PROENCA R, MAFFEI M, BARONE M, LEOPOLD L, FRIEDMAN JM: Positional cloning of the mouse obese gene and its human homologue. Nature 372: 425-432, 1994. 